\title{
A Ducted Horizontal Wind Turbine for Efficient Generation
}

\author{
I.H. Al-Bahadly and A.F.T. Petersen \\ Massey University \\ New Zealand
}

\section{Introduction}

This chapter investigates ducted turbines for the use of wind power generation. The interest for this grew from the ever increasing demand for energy. After investigating the nature of the three bladed wind turbines, it became apparent that the machines were not very efficient, expensive and have a limited fatigue life.

The ducted twin turbine wind power generator is proposed in this chapter and a comparison in performance has been carried out between the ducted turbine and the conventional turbine. The ducted turbine has the ability to accelerate the air flow through a converging intake thereby increasing the power that can be extracted from the air flow. As the wind passes through a converging duct the velocity increases while the pressure decreases. The power extracted has a cubic relationship to wind velocity where as the relation to pressure is linear.

The need for energy consumes our society. As technology has advanced in certain areas the ability to produce power has had to keep pace with the ever increasing demands. There always seems to be an energy-crisis weather contrived or real, and society allows the pollution of our environment in the name of power production.

Power production with traditional means has polluted our planet. Hydro power dams release carbon that was locked up in the trees and plants that were drowned during the filling of the dam. Any sort of fossil fuel powered plant releases carbon into the environment during the combustion process. Nuclear plants are generally unpopular and will not be accepted in New Zealand for a very long time.

Renewable, environmentally friendly, clean, safe, even wholesome, are the types of adjectives we should be using to describe power production. Wind energy is the closest we may have at present that may be considered to fit into those criteria. Certain aspects such as noise and blade flash are a concern. The ducted twin turbine is proposed in this report as an environmentally friendly, safe alternative method of power production from renewable sources.

The ducted twin turbine wind power generator is proposed in this chapter and a comparison in performance has been carried out between the ducted turbine and the conventional turbine. The ducted turbine has the ability to accelerate the air flow through a converging intake thereby increasing the power that can be extracted from the air flow. As the wind passes through a converging duct the velocity increases while the pressure decreases. The power extracted has a cubic relationship to wind velocity where as the 
relation to pressure is linear. This is exploited in the ducted turbine and gives an advantage of a factor of 17 (improvement) over the conventional turbine in theoretical calculations not including coefficients of power transformation.

This improvement in power that can be extracted from the wind is vital to the implementation of this power generation system. The system is proposed for installation and location in urban areas thereby reducing transmission losses. Blade flash is reduced and noise production is low when the formulas of (Grosveld, 1985) are applied to the situation. These factors will be vital if the generators are to be mounted close to dwellings.

To reduce complexity of design the mechanism controlling angle of attack is not built into the turbine blades as with conventional wind turbines. The ducted turbine uses Variable Inlet Guide Vanes (VIGVs) mounted in the air stream prior to the first stage turbine; this controls angle of attack maintaining optimum performance, while the mechanisms do not have to be mounted in confines of a hub. An annular arrangement is proposed that houses the pitch change mechanism in the nacelle or inner ducting reducing inertia on the rotating mechanism. The sensors for the control of the VIGVs will be a set of twin pitot static tubes measuring wind speed. As the turbine is constant speeding the only variable that will affect angle of attack is wind velocity. This is accounted for by the VIGVs as the adjustments are made the air flow is offered to the first stage turbine at the optimum angle of attack; this is the induced swirl motion from the VIGVs.

Overall this work provides an alternative to the power production systems that are available on the market. There have been similar systems produced and some early patients filed, yet the ducted system is not common, perhaps due to cost. But as more people object to the construction and expansion of wind farms full of conventional turbines, then other systems will have to be investigated. Perhaps the quieter, smaller, more efficient twin ducted wind turbine power generator.

Clean, renewable, affordable, safe, efficient, and non-invasive are the terms we need to describe our power generation systems. The environment cannot keep absorbing the industrial poisons that are the by products of modern humanities lifestyle. Coal fired power plants place carbon into the atmosphere, hydro dams cover and drowns forests that release carbon into the atmosphere during decomposition; LPG/LNG fired gas turbine power generators discharge carbon into the atmosphere, and nuclear power generation is politically unacceptable in New Zealand. The reasonable options that are left are wind and wave (tidal) power generation.

Wind turbine generation is a system that will provide clean power at an affordable rate from renewable resources. Safety and efficiency are the two areas of wind power generation that are debatable at present.

Wind energy has been touted as the energy generating saviour. It is branded renewable; that is it will be available for future generations and the 'reserve' does not diminish with use. Wind turbines also create carbon credits as the $\mathrm{CO}_{2}$ displaced by each kilowatt of energy generated that would have otherwise been generated by a fossil fuel powered station. This has lead to the increase in profitability of existing turbines in their operation.

The use of wind power dates back as long as history itself; with the use of sail harnessing the wind to power boats and ships alike. Holland would not be as it is without the use of wind to power the water pumps that held back the sea and the stones that milled the flour. Dutch settlers took the wind mill to the United States where, in the mid 1800's, it evolved into the multi-bladed wind turbine that was synonymous with the older generation cowboy movies. According to (Mathew, 2006), between 1850 and 1930 over six million of these wind turbines were sold, these were primarily used to lift water from ground wells. 
(Mathew, 2006) recognises Denmark as the first place where a purpose built wind turbine power generator was built, this occurred about 1890. At the same time a twelve kilowatt generator was built in Cleveland, Ohio, this sported a set of step-up gears to the generator.

By 1910, hundreds of generators were supplying electricity to villages in Denmark, and by 1925 small generators, $0.2-3 \mathrm{~kW}$, were available in the United States to charge batteries. These wind turbines were of a two or three blade configuration with an aerodynamic consideration to the shape of the cross section.

At the beginning of 2007 the total installed and operational capacity of wind turbines in New Zealand was 170.8 MW (The New Zealand Wind Energy Association, 2007). The installed capacity at the beginning of 2004 was 36.3 mega watts (MW): In other words this is equivalent to an increase in installed wind energy capacity of $470 \%$ - most of this occurred during 2004.

$151 \mathrm{MW}$ of new capacity is currently under construction and when this is commissioned during the year the total installed capacity in New Zealand will nearly double to $321.8 \mathrm{MW}$.

Today there are 7 wind farms in North and South Island (or 9 if you count the staged Tararua and Hau Nui developments as two separate sites) and with the growth of this industry the generation capacity will only increase. Although, there is a need for renewable power generation in the future, public objection to the erection of large scale wind farms has increased.

The lobby group against the expansion of the wind farm expansion cited:

- Low frequency noise pollution

- Blade flash

- $\quad$ Spoiling the natural aesthetics

As the factors that would depress real estate prices, raise health issues and create a general annoyance. A ducted turbine may be a possible solution for some of these problems (Dannecker and Grant, 2002; Hu and Cheng, 2008).

\section{The proposed system}

The optimisation of the wind turbine and ducting assembly is the focus of this work and concentrates on the interface between the wind and the ducting assembly. The specifications for the generator were set as a goal for us to attain or beat, these are:

\begin{tabular}{|l|l|}
\hline Rotational speed & $300 \mathrm{rpm}$ \\
\hline Power & $3 \mathrm{~kW}$ \\
\hline Efficiency & $95 \%$ \\
\hline Diameter of the generator housing & $250 \mathrm{~mm}$ (fixed) \\
\hline Generator drive & gearless \\
\hline
\end{tabular}

Setting these specifications provided a foundation from which to build the design. Other specifications were not constrained, such as torque, thereby allowing any extra power captured from the wind to be realised as current. Typically the wind strength is not constant and allowing an unconstrained parameter allows the design to harness various levels of power, when available. 
A ducted turbine with the generator mounted on a common shaft is the arrangement investigated in this work. Investigation into this system indicates a possibility of reducing the affects created by the larger wind generators.

Another prospect of this turbine will be the ability to site this item close to built-up areas. As noise and blade flash is reduced these items will be mounted directly onto buildings and in urban areas where the power is used, and any surplus sold to the power distribution company. This will; also have the affect of reducing transmission losses as power production will occur on site.

The ducted turbine has not been a popular choice with wind turbine designers. The cheaper option has been the three bladed, low rotational speed turbines commonly seen in the large commercial wind farms. With micro generation, a smaller more efficient system of a ducted turbine is proposed.

Efficiencies can be gained with a ducted system as this gives the ability of accelerating the airflow through a convergent path much like a venturi. The shape of the structure becomes critical as this determines the velocity of the airflow and partial pressures that will be required to maximise the efficiencies. Consideration as to the surface finish will be critical also as this affects the size or depth of the vena contractor and the characteristics of the airflow.

The ducted twin screw design chosen, has the ability to greatly increase the power that can be extracted from the airflow. Simply put the theoretical power that can be extracted is:

Power $(\mathrm{W})=1 / 2$ * $\left(\rho \operatorname{air}\left(\mathrm{kg} / \mathrm{m}^{3}\right)\right)$ * $\left(\right.$ turbine swept area $\left.\left(\mathrm{m}^{2}\right)\right) *(\text { wind velocity }(\mathrm{m} / \mathrm{sec}))^{3}$

$$
\text { Power }=1 / 2 * \rho * \text { TSA *V3 }
$$

This shows that power is directly proportional to half the cube of the wind velocity.

\subsection{Acceleration of airflow velocity}

Giovanni Battista Venturi (1746 - 1822), accredited with the effect named after him, is an example of Bernoulli's principle of incompressible gasses where an acceleration of airflow must occur through a constriction to satisfy the equation of continuity.

$$
\mathrm{Pa}+1 / 2 \rho \mathrm{V}^{2}+\rho \mathrm{g} \mathrm{h}=\mathrm{constant}
$$

From this we can derive,

$$
\mathrm{Pa}_{1}-\mathrm{Pa}_{2}=1 / 2 \rho\left(\mathrm{V}^{2} 2-\mathrm{V}^{2}{ }_{1}\right)
$$

And,

$$
A_{1} * V_{1}=A_{2} * V_{2}
$$

Where:

$\begin{array}{lll}\mathrm{A} & = & \text { area, } \\ \mathrm{V} & = & \text { velocity, } \\ \rho & = & \text { density of fluid, } \\ \mathrm{TSA} & = & \text { turbine swept area, } \\ \mathrm{g} & = & \text { acceleration constant, } \\ \mathrm{h} & = & \text { height, } \\ \mathrm{Pa} & = & \text { fluid pressure. }\end{array}$

The acceleration of the airflow was achieved with the use of a converging duct. This is illustrated in the diagram of Fig.1. 


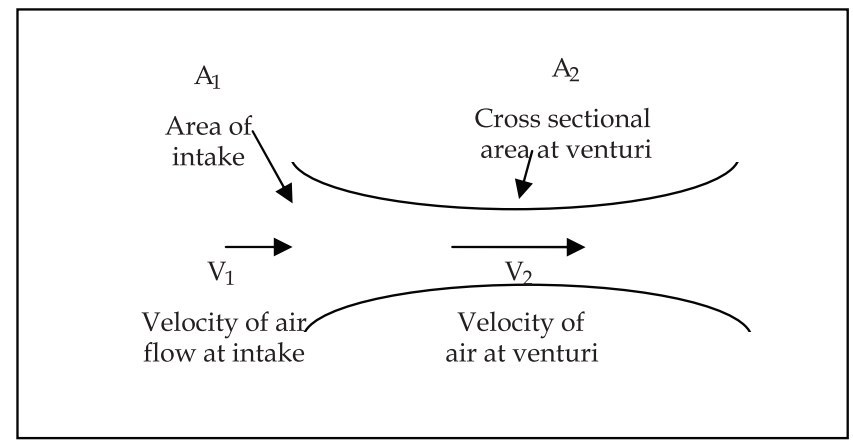

Fig. 1. Illustration of the venture equation maintaining continuity

Therefore,

$$
\mathrm{V}_{2}=\left(\mathrm{A}_{1} * \mathrm{~V}_{1}\right) / \mathrm{A}_{2}
$$

Then by placing the wind turbine inside a convergent duct we should see increased efficiencies as the airflow is accelerated through the venturi. Aside from this advantage, gains will also be made with the reduction of span-wise flow and the elimination of blade tip vortices. According to (Spera, 1994) a six percent reduction in drag can be gained by the elimination of blade tip vortices.

Noise will be reduced as more effective control of airflow over the turbine blades will be possible and acoustic relationships will be examined. By controlling the angle of attack of the airflow entering the ducting the design of the blades can be optimised for a narrow range of aerodynamic conditions, this can provide the opportunity to reduce the compromises that are normal with aerofoil design. This will enable positioning of these wind generators closer to populated areas.

An iterative approach to the development of this turbine was pursued. The software package used was EDF.lab. EDF.lab is a program designed to simulate fluid flows through a structure. It contains a solidworks modeler and may prove affective with the design process.

\section{System design}

A relationship between shape and airflow was envisaged and the areas in which the advantages to efficiency were to be sought. These were:

- Acceleration of airflow velocity

- Reduction/elimination of blade tip vortices

- Reduction of span-wise flow

- Gearless transfer of power to the generator core.

Gearless transfer of power is being achieved through the efforts of incorporating a switched reluctance generator (Chen, 2008; Zhao et al, 2009). This should enable efficient power generation without the need to incorporate step-up gear systems.

According to (Mathew, 2006), the power available in the wind can be calculated from its kinetic energy. This shall be examined at this stage although losses occur transitioning from wind kinetic energy to turbine rotational energy this can be described by a coefficient. Actual power will be discussed later in this report.

$$
E=1 / 2 * m * V^{2}
$$


If we consider the mass in terms of density and volume

Dimensional analysis gives:

$$
\begin{gathered}
E=1 / 2 * \rho * V * V^{2} \\
E=1 / 2 * \rho * V^{3}
\end{gathered}
$$

The air flow that interacts with the turbine is offered up to the front face of the rotor, this is referred to as the Turbine Swept Area (TSA). Therefore (Mathew, 2006) describes the parcel of air offered as having a cross sectional area of that of the TSA and thickness equivalent to the wind velocity. Hence energy per unit time is:

Power $(\mathrm{W})=1 / 2$ * $\left(\rho\right.$ air $\left.\left(\mathrm{kg} / \mathrm{m}^{3}\right)\right)$ * (turbine swept area $\left.\left(\mathrm{m}^{2}\right)\right) *(\text { wind velocity }(\mathrm{m} / \mathrm{sec}))^{3}$ as shown in equation (1).

If we look at the relationships between the factors of the power equation we notice a linear relation between density and power, where as, there exists a cubic relation between velocity and power. This will be exploited with the ducted turbine design.

The density will be affected by the acceleration of the air flow due to the venturi effect. To investigate the change in density to the air flow we must assume dry as being an ideal gas then apply the ideal gas law equation:

$$
\mathrm{Pa} * \mathrm{Vg}=\mathrm{n} * \mathrm{R} * \mathrm{~T}
$$

Where, $\mathrm{Pa}=$ pressure, $\mathrm{Vg}=$ volume of gas, $\mathrm{n}=$ number of kilo moles, $\mathrm{R}=$ gas constant, $\mathrm{T}=$ Temperature Kelvin, $\mathrm{m}=$ mass.

If we consider the density of air as:

$$
\rho=\frac{m}{V g}
$$

Then from equations 8 and 9 we can calculate the density of air in the turbine.

$$
\rho=\frac{n \times P a}{R \times T}
$$

\begin{tabular}{|c|c|c|c|}
\hline $\mathrm{n}$ & $=$ & 29 & $\mathrm{~kg} / \mathrm{kilo} \mathrm{mol}$ \\
\hline $\mathrm{Pa}$ & $=$ & 101221 & pascal's \\
\hline $\mathrm{R}$ & $=$ & 8.314 & $\mathrm{~J} / \mathrm{K} / \mathrm{mol}$ \\
\hline $\mathrm{T}$ & $=$ & 293 & K \\
\hline & $\frac{101221}{14 \times 293}$ & & \\
\hline$\rho$ & $=$ & 1.205 & $\mathrm{~kg} / \mathrm{m}^{3}$ \\
\hline
\end{tabular}

From the section view shown in Fig. 2, the minimum pressure gradient is $101221 \mathrm{~Pa}$. From this we can calculate the density drop in air flow through the duct using equation (10) where:

Density of air at standard temperature and pressure, $\rho=1.293 \mathrm{~kg} / \mathrm{m}^{3}$ As proof of the advantage of wind velocity over density we shall demonstrate this through a mathematical example. According to NIWA the average wind velocity in New Zealand is 6 $\mathrm{m} / \mathrm{sec}$. This value will be used as a benchmark for the calculations. 


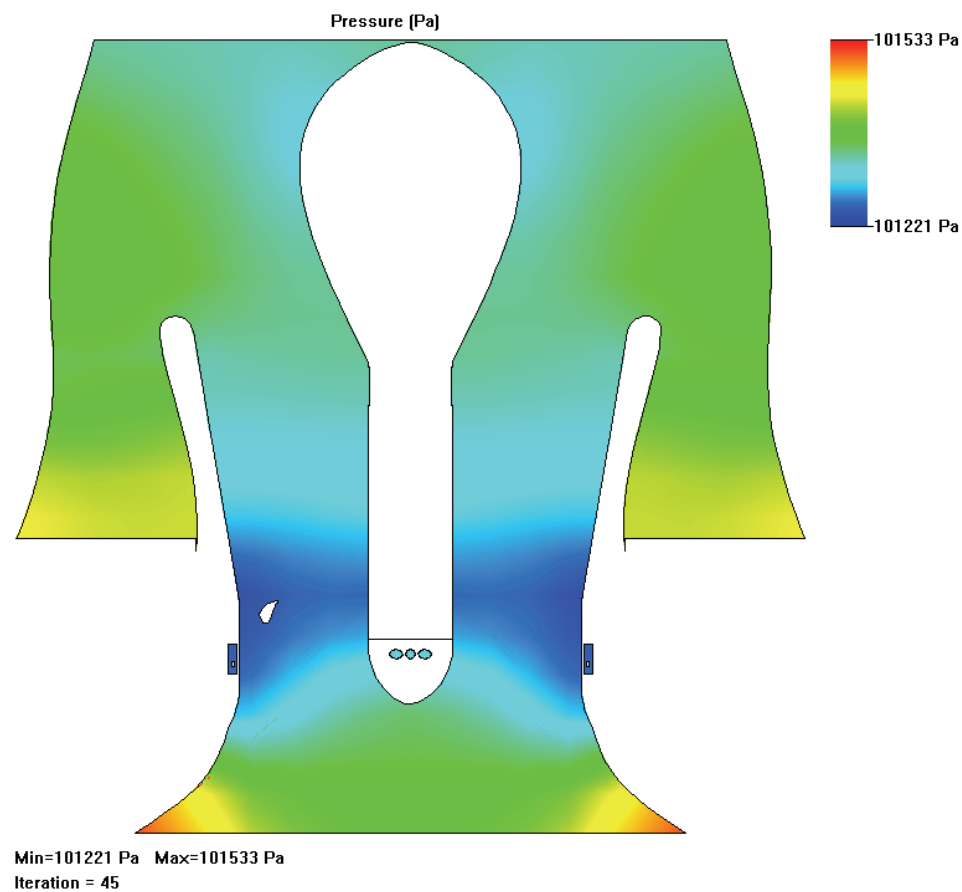

Fig. 2. Section view of turbine ducting with pressure gradients

\subsection{Calculation for condition 1}

No augmented acceleration of air flow through ducts, this condition uses the standard pole mounted turbine on a horizontal axis as shown in Fig. 3. Turbine diameter of $2 \mathrm{~m}$ with an unusable hub diameter of $0.25 \mathrm{~m}$.

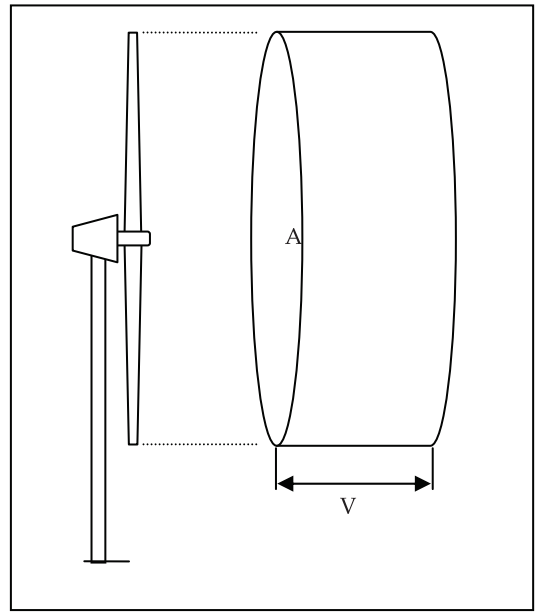

Fig. 3. Illustration of first example, standard turbine in open air 
Using equation (1). $\quad$ Power $=1 / 2 * \rho * \mathrm{TSA} * \mathrm{~V} 3$

Power $=1 / 2 * 1.293 * 3.09252 * 6^{3}$

Power $=431.9 \mathrm{~W}$

\subsection{Calculation for Condition 2}

A ducted turbine with acceleration of airflow due to the venturi affect aligned with Bernoulli's equation of continuity, as shown in Fig. 4. A drop in density is observed and will be included in the calculation.

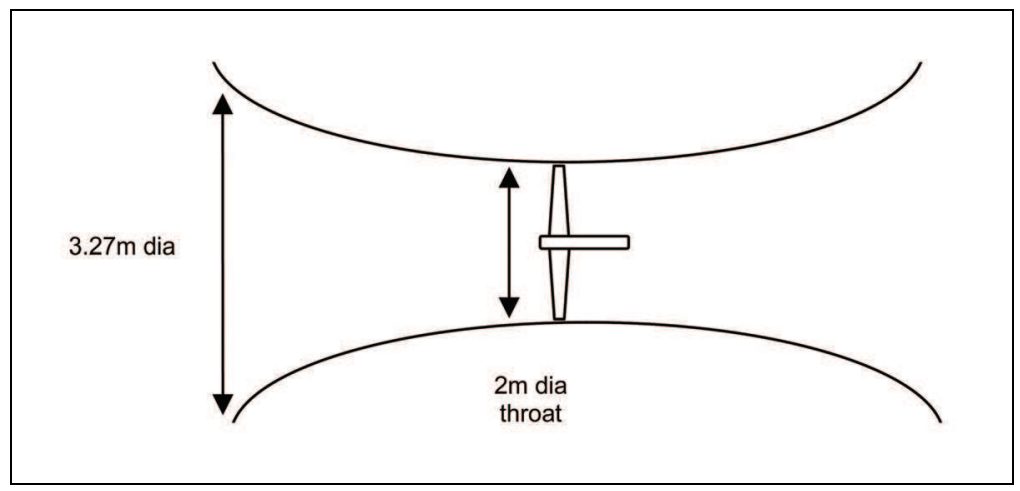

Fig. 4. Illustration of the ducted turbine, with dimensions provided

Wind velocity at the turbine. Use equation (5), $\quad V_{2}=\left(A_{1} * V_{1}\right) / A_{2}$

$$
V_{2}=\left(\pi \times 1.633^{2} \times 6\right) \div \pi
$$

$\mathrm{V}_{2} \quad=\quad 16 \mathrm{~m} / \mathrm{sec}$

From equation (10) air density at the turbine is $1.205 \mathrm{~kg} / \mathrm{m}^{3}$.

Using equation (1). Power $=1 / 2 * \rho^{*} \mathrm{TSA} * \mathrm{~V}^{3}$

Power $=1 / 2 * 1.205 * 3.09252 * 16^{3}$

Power $=7631.8 \mathrm{~W}$.

While condition 1 gave an output of $431.9 \mathrm{~W}$, condition 2 gave an output of $7631.8 \mathrm{~W}$. This provides evidence of the increase in efficiency available from a ducted wind turbine. The calculation showed an increase in efficiency of a factor of 17, this was from the same ambient wind velocity of $6 \mathrm{~m} / \mathrm{sec}$ and included the reduction in density as the air accelerates through the venturi. This is a significant increase in efficiency and can be exploited in a number of ways, either make more energy with the same size diameter turbine or make the turbine smaller. Before calculations are completed on turbine sizing, consideration must be allowed for losses during the transfer of energy from the wind to the shaft.

\subsection{Betz limit}

In 1919 Albert Betz concluded that no more than 16/27 (59.3\%) of the wind's kinetic energy could be captured by a turbine, (Gorban et al, 2001). For all the energy to be removed from the air flow and stop the wind the turbine would be a solid plate, this would not allow any transfer of kinetic energy. If the turbine some how contained one small thin blade, the 
kinetic energy would be carried away with the wind going through the rest of the swept area. The Betz limit has nothing to do with the inefficiencies of the generator and bearings, just the conversion of energy from the wind to the shaft.

As the Betz limit is the maximum efficiency that may be harnessed by the turbine, the actual efficiency is estimated between 0.35 and 0.45 , it must be noted this is turbine efficiency and does not include losses in bearings or generation. Actually it is believed that only $10-30 \%$ of the energy is converted to useful electricity.

As this project does not include the design of the turbine blade we must choose a Coefficient of Performance $\left(C_{p}\right)$.

A conservative figure of 0.35 is to be taken but (Spera, 1994) postulated 6\% savings in the elimination of blade tip vortices. This is significant and should be included in this calculation. (Mathew, 2006) gives figures of between 0.38 and 0.46 for a ducted turbine depending on the tip speed ratio $(\lambda)$, this supports the claim by (Spera, 1994) of a 0.06 increase in efficiency.

\subsection{Blade tip vortices}

Blade tip (wing tip) vortices are created when air rushes from the high pressure area 'beneath' the lifting surface to the low pressure area 'above' the lifting surface. This occurs without the air travelling cord-wise from leading edge to trailing edge. Fig. 5 shows illustration of a simple aerofoil and position of pressure gradients. Fig. 6 shows the direction of airflow.

As the air rushes from the high to the low pressure area two losses occur, reduction in the efficiency of the lifting body from span-wise flow and extra interference drag from the generation of blade tip vortices.

Energy is transferred from the motion of the blade and is used to accelerate the vortex airflow that spirals from the tip thereby creating drag.

The ducted turbine does not generate any vortices and the tip clearances are small enough to eliminate tip vortices and large enough to clear the vena contractor area. Considering the affect of the ducted turbine with respect to span-wise flow and blade tip vortices, the $6 \%$ (Spera, 1994) attributes to the deterioration of efficiency will be added to the $0.35 \mathrm{Cp}$ to give a value of $0.41 \mathrm{Cp}$.

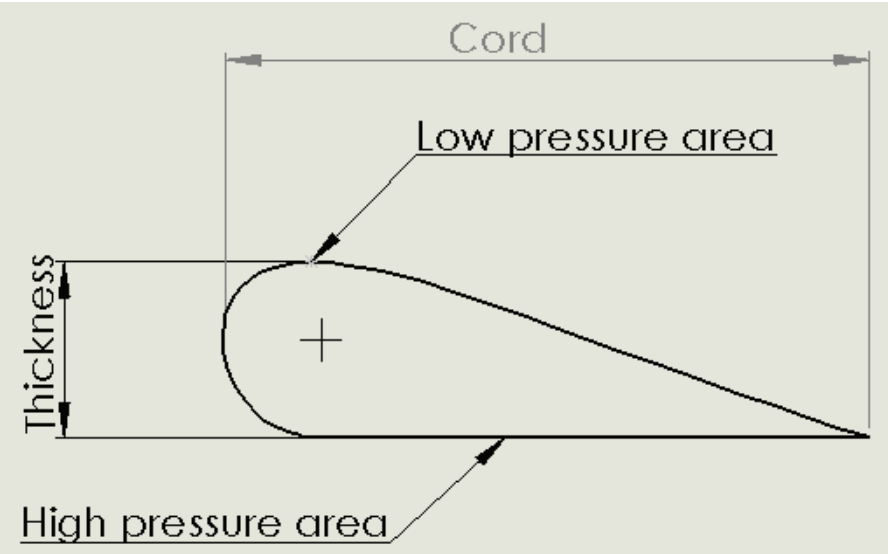

Fig. 5. Illustration of a simple aerofoil and position of pressure gradients 


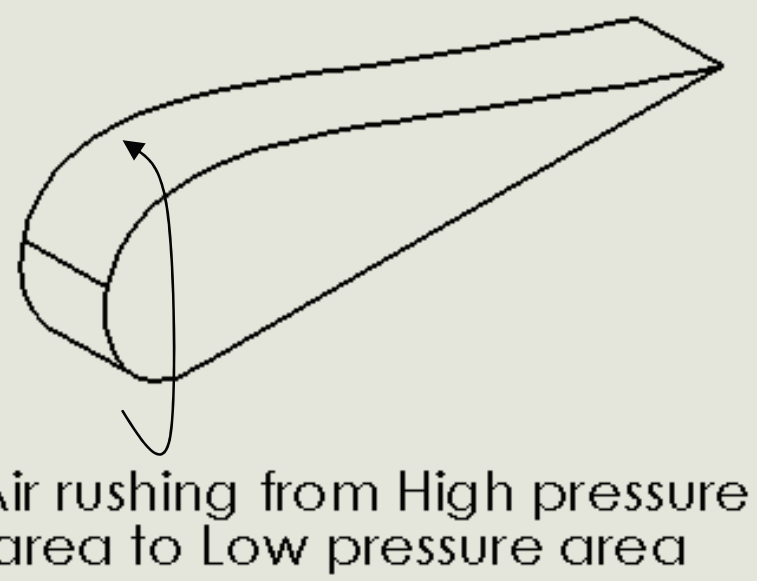

Fig. 6. Direction of airflow

\subsection{Actual power}

As discussed so far power contained in a parcel of wind is vastly different to that extracted by a wind turbine. The ducted turbine has an estimated $C_{p}$ of 0.41 .

According to (Kenttield, 1996), the expression between coefficient of power an actual power is:

$$
C p=\frac{2 \times P_{T}}{\rho \times T S A \times V^{3}}=\frac{2 \times T_{T} \times \Omega}{\rho \times T S A \times V^{3}}
$$

Where, $\Omega$ = angular velocity, $\mathrm{T}_{\mathrm{T}}=$ actual torque

Therefore, rearranging,

$\mathrm{P}_{\mathrm{T}} \quad=\quad 1 / 2 * \rho * \mathrm{TSA} * \mathrm{~V}^{3}{ }^{*} \mathrm{C}_{\mathrm{p}}$

Where, $\mathrm{P}_{\mathrm{T}}=$ Total actual power.

$\mathrm{P}_{\mathrm{T}} \quad=\quad 1 / 2 * 1.205 * 3.09252 * 16^{3} * 0.41$

$\mathrm{P}_{\mathrm{T}} \quad=\quad 3129.06 \mathrm{~W}$

Assume actual power at $3 \mathrm{~kW}$.

\subsection{Actual torque}

To calculate torque first we must investigate the importance of tip speed ratio. The relative speed between the wind and turbine is important. If the wind is at high velocity and the turbine is at relatively low rotational speed, then the wind may be able to pass through the rotor without interacting with it. This is vital as any wind that does not interact is kinetic energy that is wasted. As the design parameters for this project set the rotational speed of the turbine at $300 \mathrm{rpm}$ the turbine was designed with 8 blades, although this may not optimise the relation between wind velocity and 'obstructing' the duct it ensures the removal of energy from the stream.

Inlet guide vanes improve the efficiency of power extraction by ensuring the optimum angle of attack of the air flow onto the turbines. Using the guide vanes ensures our calculations are 
conservative and if this project goes from theory to design, there is confidence that design performance will be exceeded.

The tip speed ratio $(\lambda)$ is the ratio between the peripheral speed of the turbine and the wind velocity. According to (Mathew, 2006) is calculated:

$$
\lambda=\frac{R \times \Omega}{V}=\frac{2 \times \pi \times N \times R}{V}
$$

Where, $\mathrm{R}=$ radius of the rotor, $\Omega=$ angular velocity $(\mathrm{rad} / \mathrm{sec}), \mathrm{N}=$ rotational speed of the rotor,

Also the coefficient of torque is expressed,

$$
C_{T}=\frac{2 \times T_{T}}{\rho \times T S A \times V^{2} \times R}
$$

If we divide equation (11) by equation (13), then we get,

$$
\lambda=\frac{C_{P}}{C_{T}}=\frac{R \times \Omega}{V}
$$

Calculating $\Omega$,

$$
\Omega=\frac{2 \times \pi \times 300}{60}=31.42 \mathrm{rads} / \mathrm{sec}
$$

Tip speed ratio

$$
\lambda=\frac{1 \times 31.42}{16}=1.964
$$

Therefore the torque coefficient is,

$$
C_{T}=\frac{0.41}{1.964}=0.2087576
$$

To calculate torque we rearrange equation (13)

$\mathrm{T}_{\mathrm{T}} \quad=\quad 1 / 2 * \rho$ * TSA * $\mathrm{V} 2 * \mathrm{R} * \mathrm{C}_{\mathrm{T}}$

Therefore actual torque is:

$\mathrm{T}_{\mathrm{T}} \quad=\quad 1 / 2 * 1.205 * 3.09252 * 16^{2} * 1 * 0.2087576$

$\mathrm{T}_{\mathrm{T}} \quad=\quad 99.575 \quad \mathrm{~kg} \cdot \mathrm{m} \cdot \mathrm{sec}^{-1}$

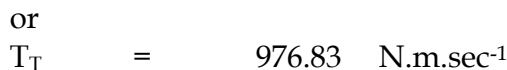

\section{Prototype}

The results from the calculations for the ducted turbine are encouraging and lead us to the design. This is to be a horizontal axis wind turbine, but this will be ducted. This was a basic Venturi with a $3.3 \mathrm{~m}$ diameter opening to the convergent duct that has its smallest diameter at the turbine, this measures $2 \mathrm{~m}$. See Fig. 7. 
The shape embodies the Venturi theory and through Bernoulli's theory of incompressible gasses and application through the equation of continuity. Applying equation (4) enables acceleration of the air flow through the turbine that is mounted $1200 \mathrm{~mm}$ from the leadingedge of the duct. This shape has been optimised to accelerate the air through the ducting.

This configuration contains two turbines on the same shaft, the second has less blades as there is not so much energy left in the airflow.

The tapering of the duct in the last $1100 \mathrm{~mm}$ to the rear of the turbine is to accommodate the stream tube.

As the air enters the turbine it obviously slows as some of the kinetic energy is removed. This implies that the air flow is slower leaving the turbine than when it entered. But the same amount of air that enters the turbine, in a given amount of time, must leave the turbine in that same time period, therefore the cross sectional area to the rear of the rotor must be greater to accommodate the slower moving scavenge air. Fig. 8. shows section view of the inner and outer shrouds.

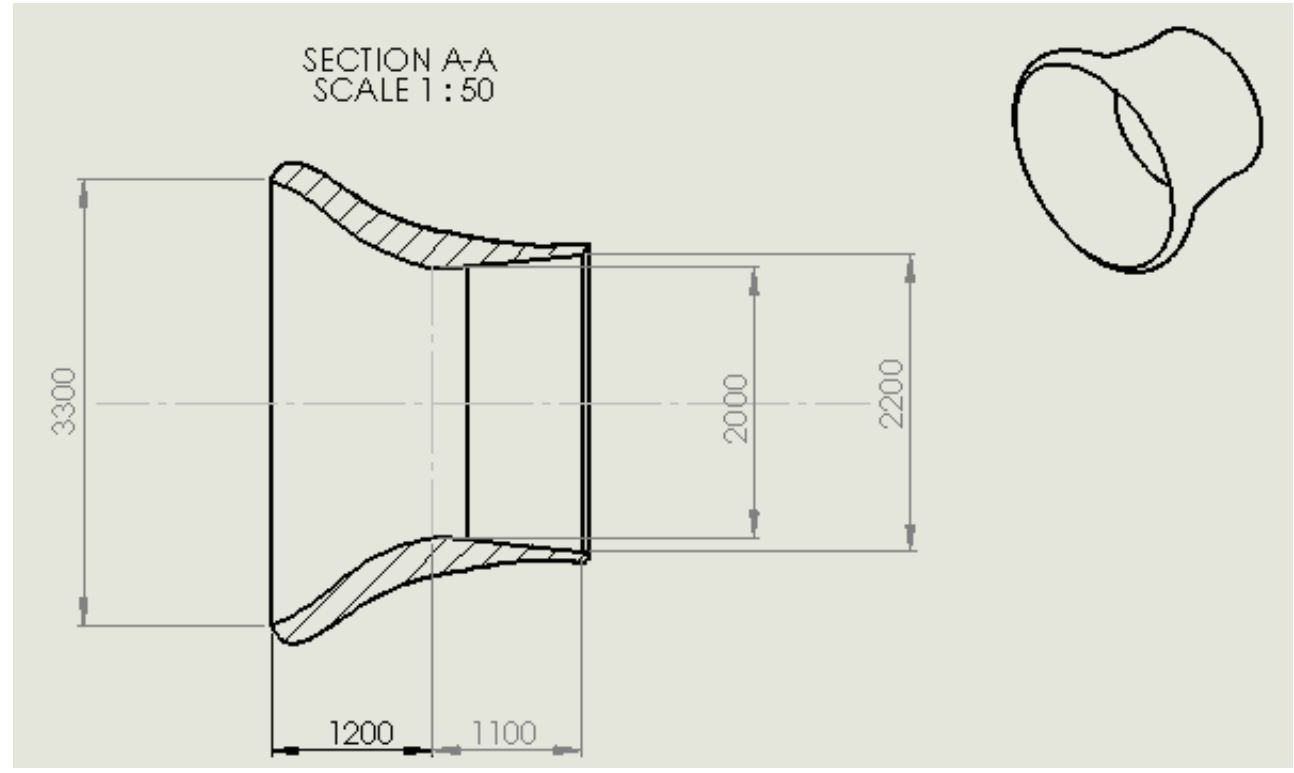

Fig. 7. Section view of the inner turbine ducting, all dimensions in $\mathrm{mm}$

A second shroud is fitted to the rear of the inner duct and draws air in through an annular orifice, this is to aid the scavenging of the air from behind the turbine. As low pressure air exists in the turbine ducting after transferring energy to the rotor, another venturi is added to lower the pressure at the rear to help scavenge the exhaust air.

As the centre of drag of the second fairing is to the rear of the pivot point this also aids weather cocking as shown in Fig. 9.

Applying equation (4) to the area where the air flow leaves the inner duct and mixes with the air from the outer duct, there is an observed narrowing of the passage. The conclusion when analysing the relationship between $A_{1}, V_{1}$ and $A_{2}, V_{2}$ is that as $A_{2}$ gets smaller relative to $A_{1}$ then $V_{2}$ increases. This principle (the venturi principle) is used where the two airflows mix. 

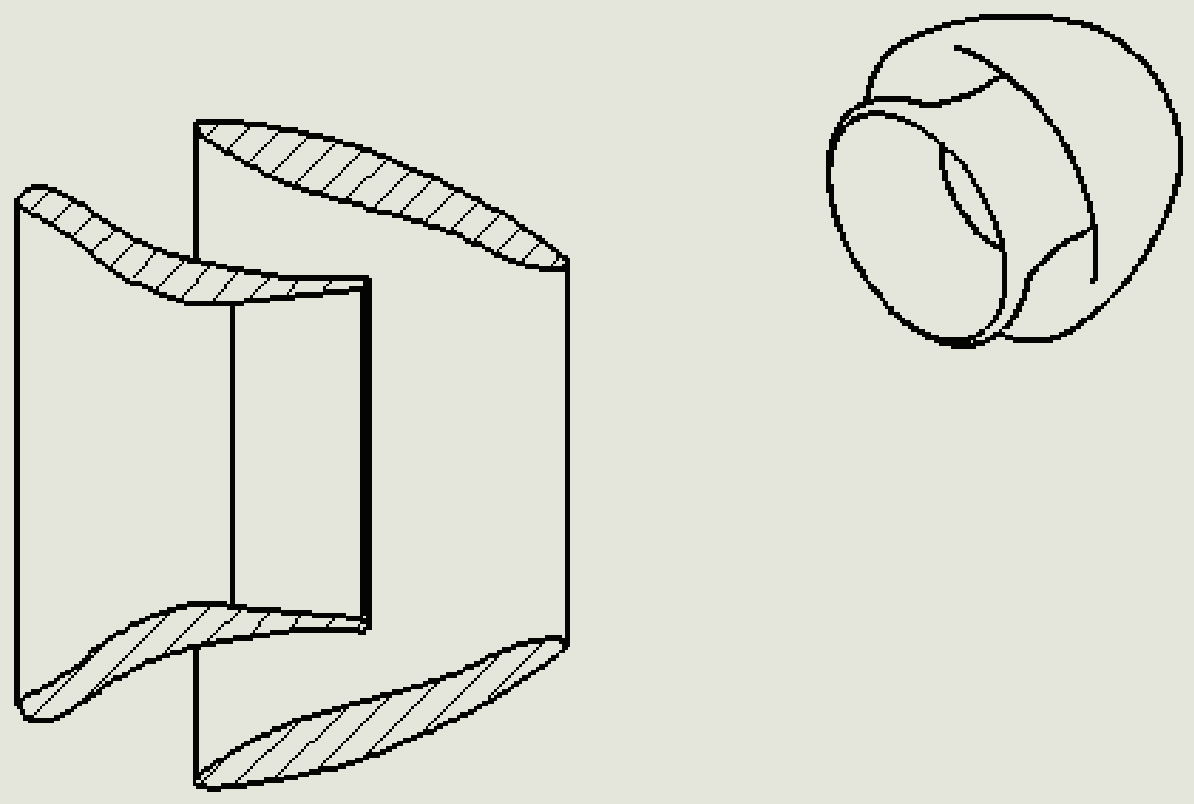

\section{SECTIONA-A}

SCALE $1: 50$

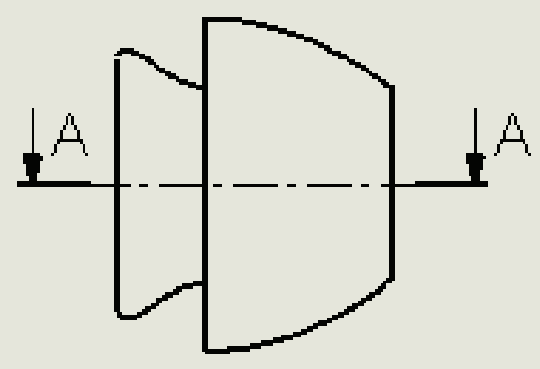

Fig. 8. Section view of the inner and outer shrouds 


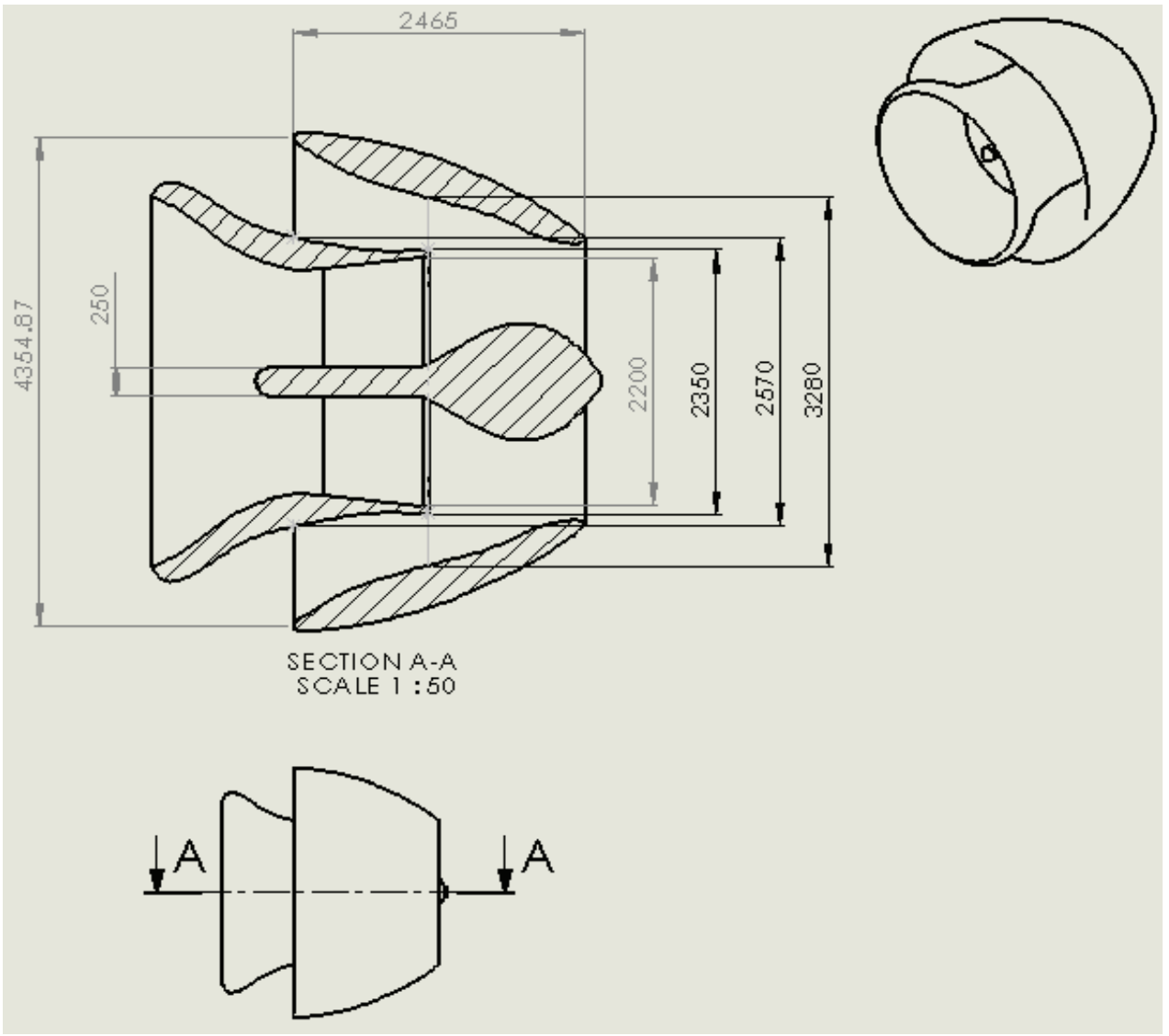

Fig. 9. Dimensioned inner and outer shrouds complete with generator fairing

\subsection{Surface finish}

The surface finish of all areas exposed to the airflow is critical. A smooth finish is required to minimise the size of the vena contractor and to reduce turbulent flow. The air travelling through the ducting is turbulent; this is defined by a dimensionless value called the Reynolds Number (Re) and is calculated:

$$
\operatorname{Re}=\frac{\rho \times V \times D}{\mu}
$$

Where, $\mathrm{D}=$ pipe diameter, $\mu=$ fluid viscosity.

The Reynolds number for fluid flow through the ducted turbine is from $1.21 \times 10^{6}$ to $2.14 \mathrm{x}$ 106. This is outside the lamina flow range, therefore surface finish is critical as it affects the Friction Factor. The easy way to determine the friction factor is with the use of the Moody chart as shown in Fig. 10.

The e/D ratio must first be calculated where, $\mathrm{e}=$ the average height of the bumps on the surface, $\mathrm{D}=$ the diameter of the pipe. 


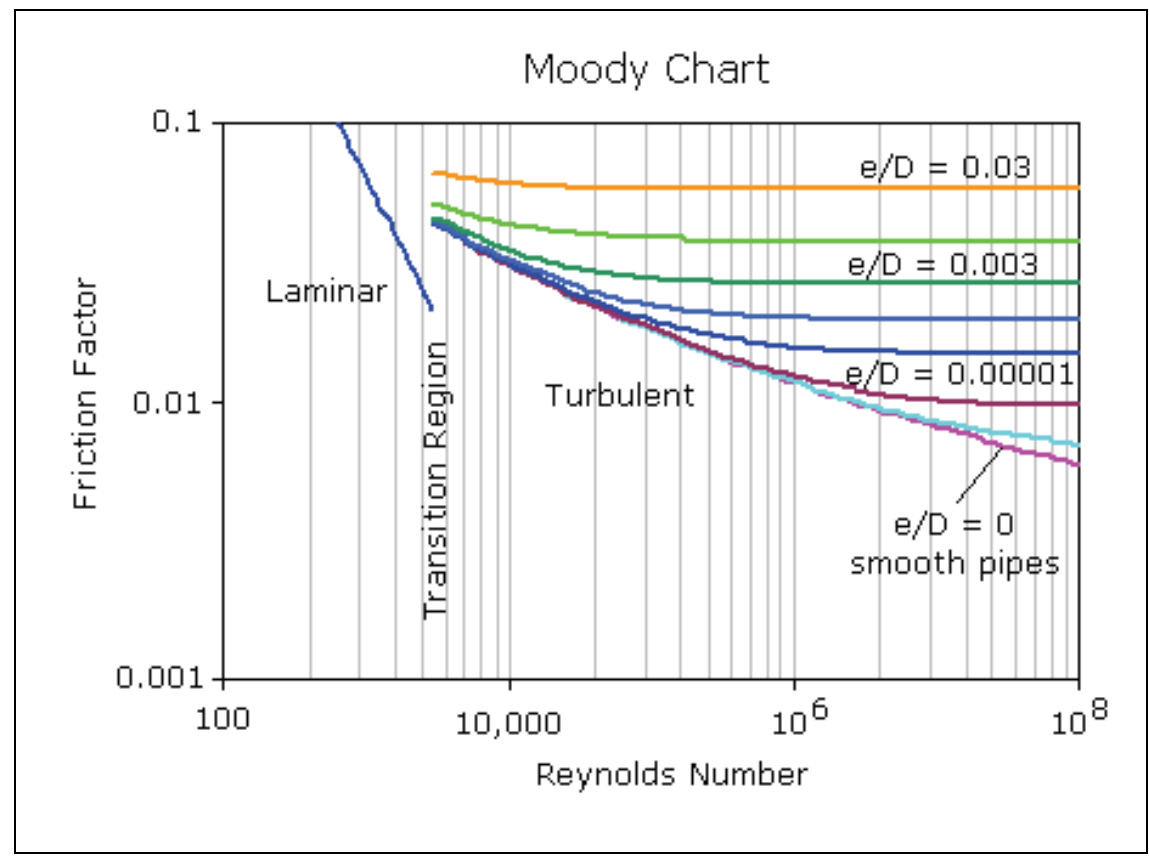

Fig. 10. Moody chart, courtesy of (eFunda, 2001)

Assume:

Plastic moulding with a surface finish of

Smaller diameter of duct

$3 \mu \mathrm{m}$

$2 \mathrm{~m}$

This gives an e/D factor of:

$1.5 \times 10^{-6}$

Applying this to the Moody chart we get a friction factor of: 0.0098

The friction factor is the multiplier that calculates the pressure drop per meter length of pipe. The pressure drop is directly proportional to the wind velocity through the ducting, hence a direct indication of kinetic energy lost. As the e/D ratio is the basis of the friction factor calculation, the only way a reduction in losses can be achieved is, either make the surface finish smoother and/or the hole larger.

\subsection{Angle of attack}

Inlet guide vanes and stators have been incorporated into the design to ensure the airflow isoffered to the turbine stages at an optimum angle of attack. For any aerofoil cross section to be efficient it has to be offered to the air flow at the correct angle of attack [see Fig. 11].

Inlet guide vanes and stators act to direct a fluid in a particular direction. In a situation where there are areas of low pressure turbulence that are present due to a change in profile or cross sectional area; then a device that will precisely alter the flow to compensate for these changes will increase efficiency.

Variable inlet guide vanes (VIGVs) can be adjusted to apply a favourable spin to the mass airflow thereby offering the stream at the most optimum angle of attack for the particular wind speed. The VIGVs can also be used in high winds where the vanes can be turned as this alleviates the need for a variable pitch turbine blade and reduces the complexity of the 
design. However, a variable pitch system is still required for the VIGVs, but this becomes less complex than the variable pitch blade as the actuating mechanism does not need to mounted on a shaft and is better suited to positioning within the nacelle.

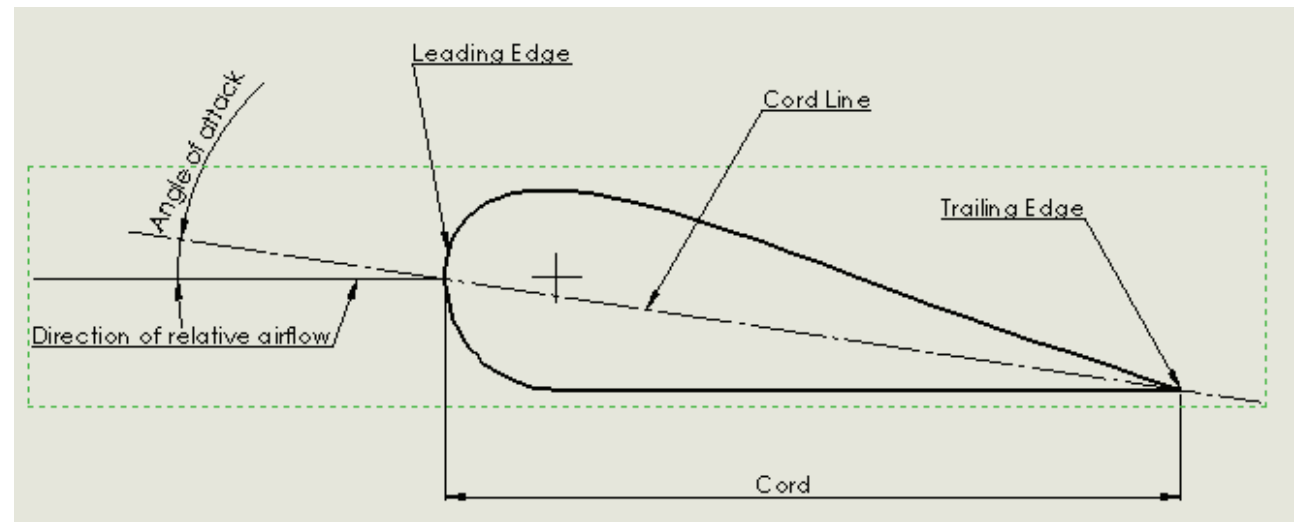

Fig. 11. Angle of attack

Stators are situated between the two turbines within the stream tube. These have a dual purpose: as a means to reduce turbulent flow by offering the airflow up to the turbine at the optimum angle of attack and, as a set of cooling fins to dissipate heat from the generator.

$\mathrm{V}_{\text {Tur }}$ is the component of the wind velocity induced by the rotation of the turbine, $\mathrm{V}_{\text {Wind }}$ is the component induced by the wind. $V_{\text {Resultant }}$ is the resultant of the previous two vectors this has its coefficients of drag and lift. $\Phi$ is the angle of attack.

Aero foils have a critical angle of attack where the maximum efficiency is attained. Depending on the aerofoil cross section $\pm 1 / 2$ a degree can be greater than the tolerance allowable to maintain maximum efficiency. Therefore it is import to maintain the optimum angle of attack.

Consider the parallelogram of forces shown on Fig. 12. For the same rotational speed of the turbine, the linear velocity changes for different points of the blade from the hub to the tip. Close to the hub of the blade $V_{\text {Tur }}$ will be short representing the slower speed, this will move the $V_{\text {Resultant }}$ thereby increasing the angle of attack $\Phi$. This will mean the aerofoil is not at its optimum at certain points. The rectification of this is to design a twist into the blade; this ensures a constant angle of attack at a fixed rotational speed.

With VIGVs, the optimum angle of attack can be maintained through a wide range of rotational speeds and wind speeds. Contemplating the parallelogram of forces in figure 13, if the vector $V_{\text {Wind }}$ was to greatly increase, the angle of attack $\Phi$ would also change. By altering the angle at which the wind was offered to the turbine, $V_{\text {Wind, }}$ would solve the angle of attack $\Phi$ to the optimum angle for greater efficiency.

Turbine blades can also be part reaction and part aerodynamic. Close to the hub blade cross sections are either reaction in cross section or, if the gain is not optimal, structural to take the high loads from centrifugal forces and fatigue from harmonics. If a section is taken close to the blade tip a more aerodynamic lifting surface will be observed. The aerodynamic shape is to optimise the aerodynamic forces to remove the kinetic energy from the airflow (Schreck et al, 2007, Schreck and Robinson, 2007). 


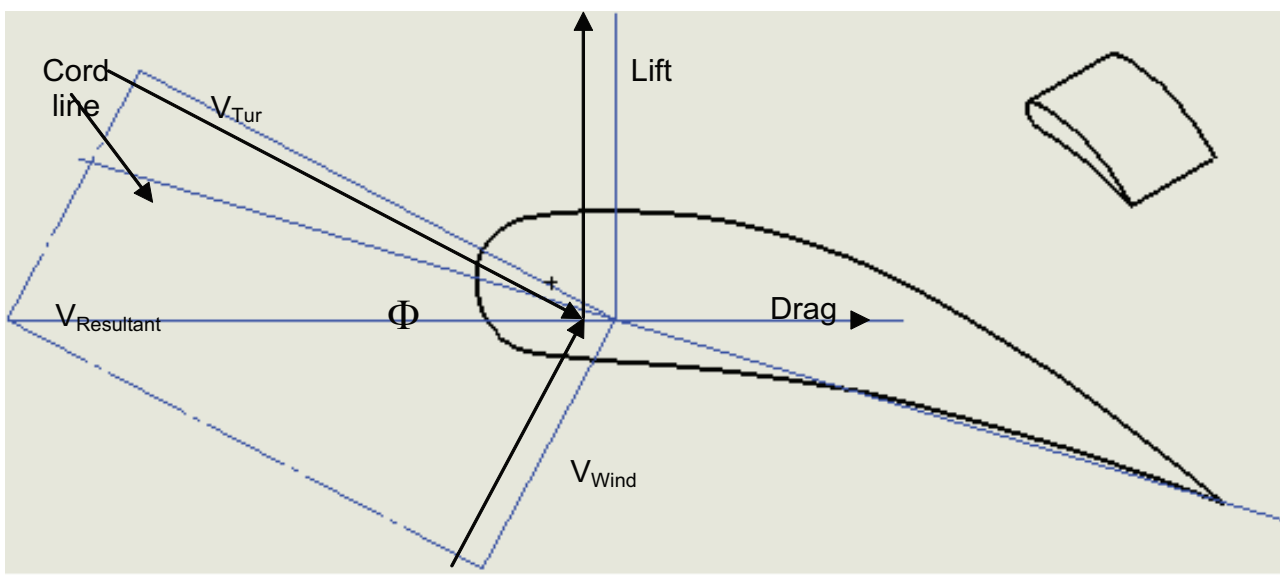

Fig. 12. Vector of forces on an aerofoil

\subsection{Vector flow}

Figure 13 depicts the vector flow through the ducted turbine. The length of the vector arrows represents relative wind speed and direction. This illustration was produced using EDF.Lab ${ }^{\mathrm{TM}}$ in conjunction with Solidworks ${ }^{\mathrm{TM}}$. The purpose of the lids depicted in yellow, orange, and green, are to define the boundaries around the design and are only used within the mathematical modelling of the turbine assembly. The vectors depict smooth flow through the system with no turbulence evident.

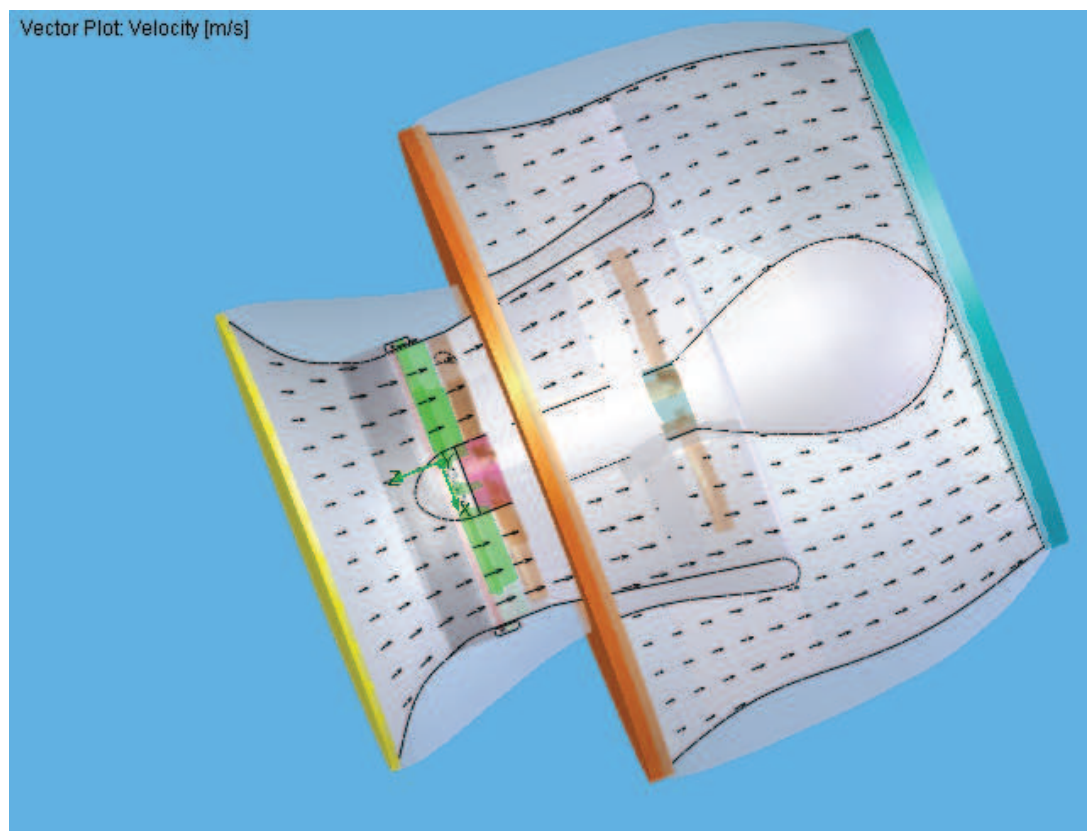

Fig. 13. A sectioned representation of vector flow through the Turbine ducting 
The turbine assembly comprises a convergent duct assembly that accelerates the air flow to the VIGVs. The VIGVs are adjustable and will guide the airflow on to the first stage turbine at the optimum angle of attack. As shown on page 34 this the angle between the resultant vector and the cord line of the aerofoil and this varies with wind velocity and rotational speed of the turbine. By maintaining the optimum angle of attack greater efficiencies can be maintained.

Control of the VIGVs will be proportional to wind speed only. As the turbine is constant speeding, $\mathrm{V}_{\text {tur }}$ is constant, therefore $\mathrm{V}_{\text {wind }}$ is the only variable. Wind velocity can be sensed using twin pitot static tubes that can be mounted diametrically opposite each other on the outside edge of the turbine intake as shown in Fig. 14. The wind speed can be read as the highest of the results received from either pitot tube.

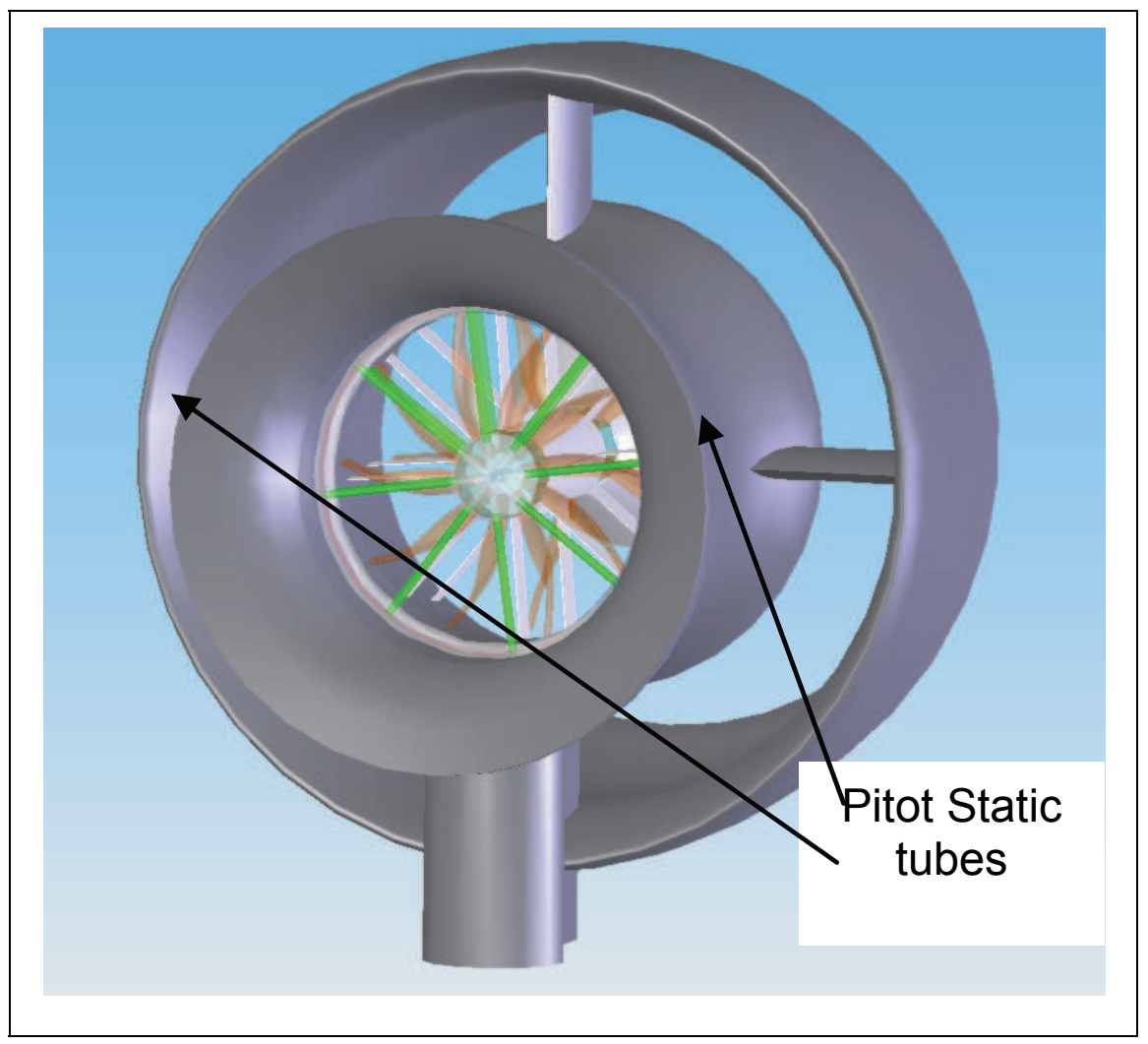

Fig. 14. Position of pitot static tubes

\section{Conclusion}

The specifications were set as a goal for us to achieve with our design. From the specification a rough design was envisaged and the first of the basic principles were 
mathematically modelled, this provided evidence that the design was feasible. Further expansion to the design was carried out and more of the fundamental mathematics was discovered that would describe the Air flow through the duct.

Power calculations were provided for the ducted turbine and the conventional turbine. These provided a direct comparison that was referred to as condition 1 and condition 2 . This showed a theoretical power rating difference of a factor of 17 , it must be shown here that the theoretical power shows the amount of power that is available in the wind flow.

The Betz limit describes that maximum amount of power that is able to be extracted from the wind flow this is 16/27 (59.3\%). A more conservative approach was taken and a coefficient of 0.41 was chosen. This provided evidence of a $3 \mathrm{~kW}$ out put.

The Reynolds number shows turbulent flow through the ducting as the number was in the order of $10^{6}$ (anything above 2000 can be considered turbulent flow). Therefore VIGVs and stators were added to reduce the possibility of vortex generation. The VIGVs also provide control of the wind flow over the turbine blades; this allows the optimum power to be extracted while reducing the boundary layer over the blade and minimising the possibility of turbulent boundary layer flow interacting with the blade trailing edge.

\section{References}

Chen H. Implementation of a three-phase switched reluctance generator system for wind power applications. In: Proceeding of the $14^{\text {th }}$ Symposium on electromagnetic launch technology, 2008.

Dannecker R, Grant A. Investigations of a building-integrated ducted wind turbine module. Wind Energ. 2002; 5:53-71.

eFunda. Smart Measure, Pipe Friction. Retrieved from, 2001; www.efunda.com/ formulae/smc_fluids/calc_pipe_friction.cfm, on 19 Jul 07.

Gorban AN, Gorlov AM, and Silantyev VM. 2001. Limits of the Turbine Efficiency for Free Fluid Flow. Journal of Energy Resources Technology, 2001; 123: 311 - 317.

Grosveld FW. Prediction of Broad Band Noise from Horizontal Axis Wind Turbines. Journal of Propulsion and Power, 1985; Vol 1, No 4.

$\mathrm{Hu} \mathrm{SY}$, Cheng JH. Innovatory designs for ducted wind turbines. J. Renewable Energy 33 (2008):1491-1498.

Kenttield JAC. The Fundamentals of Wind-Driven Water Pumps. Gordon and Breach Science Publishers. Amsterdam, Netherlands, 1996.

Mathew S. Wind Energy, Fundamentals, Resource, Analysis and Economics. Springer, Berlin, 2006.

Schreck SJ, Robinson MC. Horizontal axis wind turbine blade aerodynamics in experiments and modelling. IEEE Trans. on Energy Conversion 2007;22(1):61-70.

Schreck S, Sorenson N, and Robinson M. Aerodynamic structures and processes in rotationally augmented flow fields. Wind energy, vol. 1, no. 2, 2007.

Spera, DA. Wind Turbine Technology, Fundamental Concepts of Wind Turbine Engineering. ASME Press, New York, 1994.

The New Zealand Wind Energy Association. Current Wind Farms and Projects Under Construction. Retrieved from, 2007;www.windenergy.org.nz/FAQ/map.htm, on the 21 Mar 07. 
Zhao H, Lingzhi Y, Hanmei P, and Kunyan Z. Reseach and control of SRG for variablespeed wind application. Proceeding of the $6^{\text {th }}$ IEEE international conference IPEMC, 2009;2238-2243. 


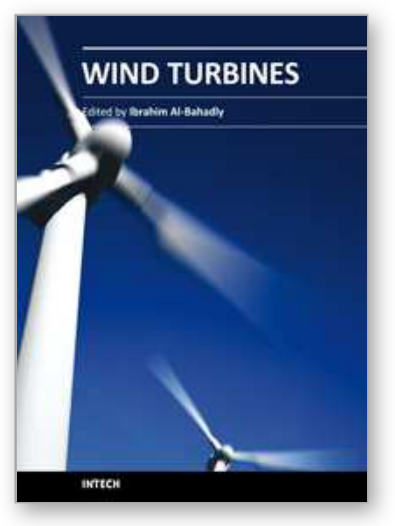

\author{
Wind Turbines \\ Edited by Dr. Ibrahim Al-Bahadly
}

ISBN 978-953-307-221-0

Hard cover, 652 pages

Publisher InTech

Published online 04, April, 2011

Published in print edition April, 2011

The area of wind energy is a rapidly evolving field and an intensive research and development has taken place in the last few years. Therefore, this book aims to provide an up-to-date comprehensive overview of the current status in the field to the research community. The research works presented in this book are divided into three main groups. The first group deals with the different types and design of the wind mills aiming for efficient, reliable and cost effective solutions. The second group deals with works tackling the use of different types of generators for wind energy. The third group is focusing on improvement in the area of control. Each chapter of the book offers detailed information on the related area of its research with the main objectives of the works carried out as well as providing a comprehensive list of references which should provide a rich platform of research to the field.

\title{
How to reference
}

In order to correctly reference this scholarly work, feel free to copy and paste the following:

I.H. Al-Bahadly and A.F.T. Petersen (2011). A Ducted Horizontal Wind Turbine for Efficient Generation, Wind Turbines, Dr. Ibrahim Al-Bahadly (Ed.), ISBN: 978-953-307-221-0, InTech, Available from: http://www.intechopen.com/books/wind-turbines/a-ducted-horizontal-wind-turbine-for-efficient-generation

\section{INTECH}

open science | open minds

\section{InTech Europe}

University Campus STeP Ri

Slavka Krautzeka 83/A

51000 Rijeka, Croatia

Phone: +385 (51) 770447

Fax: +385 (51) 686166

www.intechopen.com

\section{InTech China}

Unit 405, Office Block, Hotel Equatorial Shanghai

No.65, Yan An Road (West), Shanghai, 200040, China

中国上海市延安西路65号上海国际贵都大饭店办公楼405单元

Phone: +86-21-62489820

Fax: +86-21-62489821 
(C) 2011 The Author(s). Licensee IntechOpen. This chapter is distributed under the terms of the Creative Commons Attribution-NonCommercialShareAlike-3.0 License, which permits use, distribution and reproduction for non-commercial purposes, provided the original is properly cited and derivative works building on this content are distributed under the same license. 